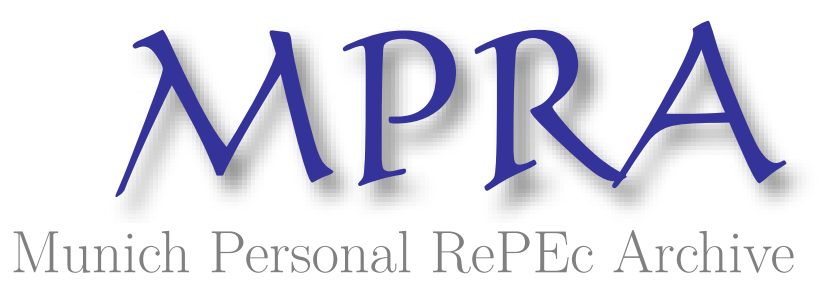

Estimating the impact of wind generation and wind forecast errors on energy prices and costs in Ireland

Swinand, Gregory P and O’Mahoney, Amy

London Economics, IPA Energy + Water Economics

2014

Online at https://mpra.ub.uni-muenchen.de/56246/

MPRA Paper No. 56246, posted 30 May 2014 03:39 UTC 


\title{
Estimating the impact of wind generation and wind forecast errors on energy prices and costs in Ireland
}

\author{
Gregory P. Swinand", London Economics, and Amy O’Mahoney", IPA Energy + Water Economics
}

\begin{abstract}
This paper studies the impact of wind generation on system costs and prices in Ireland. The need to mitigate climate change, achieve renewables energy targets, and use renewable sources of energy means that many countries are considering greater levels of wind generation in their power generation mix. The overall impact of wind generation on system costs and performance has only been studied recently, and often with limited actual data from power systems with increased wind penetration. The paper uses a unique dataset of half-hourly system demand, generation, wind forecast generation, and actual wind generation, along with Irish system marginal price (SMP) data from 2008 to autumn 2012 . An econometric time-series model of SMP as a function of forecast and realized demand and wind generation is formed. The costs of balancing and system constraints are included in the cost of 'uplift', and thus the total cost of a variety of factors is included in our estimates for Ireland. Our results suggest that each 1\% increase in wind generation reduces SMP in Ireland by about $0.06 \%$, while each 1\% wind forecast error increases SMP about $0.02 \%$. In absolute terms, though, at the mean the impact of wind forecast errors is small, or about $0.4 €$ cent/MWh-wind generated. However, the impact per MWh forecast error is about $€ 1$.
\end{abstract}

Index Terms-Cost function, econometrics, power generation economics, power system economics, wind power generation.

\section{INTRODUCTION}

While climate change continues to be one of the most important policy issues facing the developed world, the continuing pressure on the national budgets and expenditures from the economic downturn means that the costs of meeting climate change targets are increasingly at the center of policy debates.

Wind power has been seen as perhaps the best way towards meeting climate change and emissions targets by many countries, both small and large. Wind power external costs exist in total transmission system losses, system balancing costs, the cost of required reserves (both spinning and non-spinning), other ancillary services and the total cost of power generation. The cost of using wind power to meet renewables targets is of course uncertain and must be estimated. The costs to the system may exhibit scale and scope economies. The impact of increasing levels of wind power on smaller systems may be different than for larger systems and thus it is important to estimate the impacts of wind generation on system costs for a variety of systems. Finally, the external costs of wind on power systems may interact with fuel prices, market design elements, levels of competition, and other factors. Thus it is important to estimate wind system costs for a variety of systems and at different points in time.

\footnotetext{
* Greg Swinand, London Economics, gswinand(at)londecon.co.uk, and,

\# Amy O’Mahoney, IPA Energy + Water Economics, omahonea(at)tcd.ie.
} 
This study investigates the impact of wind power on electricity costs in Ireland. Ireland is a particularly interesting case in which to study wind-power system costs for a variety of reasons. The Irish electricity market has a number of characteristics which makes it an ideal case study for electricity market research. It is somewhat unique in that it operates in two different jurisdictions and operates with dual currencies. It is a small island system, with an installed capacity of $9 \mathrm{GW}$ of conventional capacity of which approximately $2 \mathrm{GW}$ is excess capacity and planning reserve, and limited interconnection to the GB system through two interconnectors. Because of the system's small capacity and low interconnection (the interconnectors with Great Britain-GB) are capable of importing 500 MW each and exporting slightly less), the percentage increase and expected overall proportion of wind power in Ireland will be large. ${ }^{1}$

The all-island system has a high proportion of installed wind capacity equivalent to roughly $18 \%$ of total installed capacity. This has been used to generate up to $49.9 \%$ of the island's electricity demand; wind is curtailed if it exceeds $50 \%$ of total system load at any given time.

A second element perhaps unique to Ireland relates to its market design. While the generation market is fully competitive, the prices bid by generators into the power pool are for practical purposes regulated; generators must bid their marginal cost (or average variable cost) of generation, with fuel prices and thermal efficiency of generation units checked by the regulator. A straightforward merit order and the day-ahead forecasts of demand and wind generation forms a day-ahead dispatch schedule and a daily set of half-hourly system marginal prices (ex ante SMP). In addition, the cost of constraints and other factors, and balancing, are included in the ex post SMP paid to generators, which adjusts the day-ahead SMP. This means that the final price paid to generators for the power they generate is not finalized until four days ex post. The market data are also all available online from SEMO (the market operator). Further, wind forecast and actual generation outturn data are available from Eirgrid (the ROI TSO). Thus the possibility of studying the total cost of wind power on the system, and including the impacts of wind forecast errors is made possible by the Irish data and market design. This is different from a previous study of the GB wind system balancing costs [6], which a) focused only on balancing and b) did not include the difference between forecast and actual outturn wind generation.

\section{REVIEW OF LITERATURE}

The overall system cost and price impacts as a result of wind are likely ambiguous, as different characteristics of wind affect cost both positively and negatively. For example, baseload units, such as coal, may be cycled more frequently with the introduction of variable generation sources such as wind [5]. This in turn could result in significant increases in a variety of costs, including impacting the merit order (flexible plant may run ahead of inflexible plant), and operation and maintenance (O\&M) and start costs. On the other hand, thermal units displaced by wind will lead to a fuel cost saving as wind has zero fuel costs. ${ }^{2}$ The cost of providing reserve may also increase as wind penetration rises; as wind output is not as constant relative to traditional thermal units [2],[3].

A number of previous studies have estimated the cost of wind generation on the system. The results from the studies reviewed by [7] and [8] are neatly summarized by a figure they present. They conclude that system balancing costs increase by about $€ 1-4 / \mathrm{MWh}$ of wind power produced, for system wind penetration levels up to $20 \%$ of power generated. They also demonstrate that the methodologies used so far to examine the issue of balancing cost implications of wind power have mostly relied on simulation approaches. Historically in many countries, wind generation has contributed to a negligible degree to the overall generation mix, so that empirical studies have been of limited value. Moreover, the seasonal and annual variation in energy consumption means that meaningful analysis likely requires time series of several years, which are only now becoming available.

Reference [3] notes that some of the savings associated with the fuel saving in the marginal price may simply be transferred to the uplift and capacity payment mechanisms. This would occur if units are switched on and off more frequently, or if generators require additional payments in order to recover their lost-energy operating margin.

\footnotetext{
${ }^{1}$ Planned targets are for about $40 \%$ of energy to come from wind.

${ }^{2}$ For a more detailed investigation, see Denny \& O’Malley, 2007.
} 


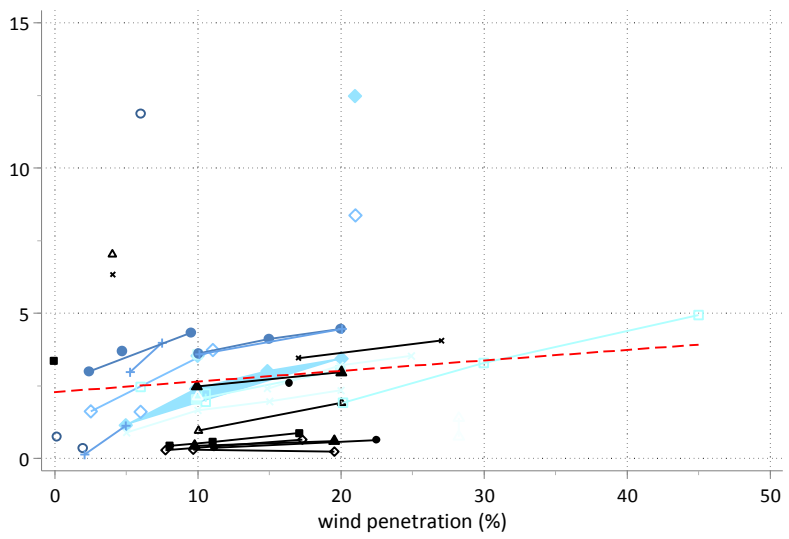

Figure 1 Range of findings on the increase in balancing costs due to intermittent generation. (Note: the figure summarises 36 estimates from 22 studies from Europe and the USA. It is based on Fig. 5 in [8] and Fig. 3.2 in [7]. £ values from [1] have been recalculated using exchange rates at the date of publication and adjusted by the Eurostat industry producer price index for "electricity, gas, steam and air conditioning supply". The dashed red line is a regression line through all observations.) (figure found in [6]).

\section{DATA}

The dataset for the study comes from publically available data on the SEMO and Eirgrid websites [9], [10]. SEMO is a joint venture between Eirgrid plc - the Transmission System Operator (TSO) in the Republic of Ireland - and SONI Limited, the TSO in Northern Ireland. All data are actual historic output from the system, recorded on a halfhourly ${ }^{3}$ basis from January 2008 to December 2012. Such high-frequency micro-data enabled us to test whether short-term changes in the wind generation in the Republic of Ireland had any impact on system costs.

Table 1 provides summary statistics for each of the variables included in our model specification.

Table 1: Summary Statistics Key Variables

\begin{tabular}{lccccc}
\hline Variable & Obs & $\begin{array}{c}\text { Mean } \\
\text { (levels) }\end{array}$ & $\begin{array}{c}\text { Std. } \\
\text { Dev. }\end{array}$ & Min & Max \\
\hline $\begin{array}{l}\text { lnep2_sm } \\
\text { p }\end{array}$ & 88237 & 54.33 & 0.436 & 0.068 & 6.866 \\
lndem & 70293 & 2,916 & 0.222 & 7.359 & 8.534 \\
lndem2 & 70293 & $\begin{array}{c}4.58 \mathrm{E}+2 \\
7\end{array}$ & 3.524 & 54.162 & 72.825 \\
$\begin{array}{l}\text { lnwindge } \\
\text { n }\end{array}$ & 70297 & 255.19 & 1.061 & 0.000 & 7.313 \\
$\begin{array}{l}\text { lnwindfc_- } \\
\text { e } 50218\end{array}$ & 0.88 & 0.442 & -3.952 & 2.032 \\
$\begin{array}{l}\text { lnwindfc_ } \\
\text { e2 }\end{array}$ & 50218 & 1.23 & 0.528 & 0.000 & 15.620 \\
lngas_e_c & 87299 & $2.02 \mathrm{E}+0$ & 0.329 & 10.865 & 12.973 \\
o2 & 5 & & 3.536 & 4.840 \\
lnoil_e_c & 87299 & 76.94 & 0.276 & 3.54 \\
o2 & & & & &
\end{tabular}

lnep2_smp represents the logged ex post system marginal price (SMP) on the all-island electricity system on a half hourly basis - this will be the dependent variable.

\footnotetext{
${ }^{3}$ Wind and demand from EirGrid are actually available for each quarter hour, but we aggregate these data to half-hourly.
} 
Indem represents the logged electricity demand on the system. We expect that demand should have a positive effect on the SMP, because as more units are dispatched the associated fuel costs will increase accordingly. We include its square as we do not expect the price of electricity to be linearly affected by demand.

lnwindgen is the logged wind output from the Republic of Ireland. We expect that wind will reduce the SMP as it offsets more expensive units and their fuel inputs from being dispatched and entering the supply curve.

lnwindfc_e the logged wind forecast error. We expect that this should have a positive impact on the SMP, as errors in forecasting must be met by added flexible generation. We also included as regressors the log of natural gas prices, inclusive of $\mathrm{CO}_{2}$ cost, in Euro/MWh, as lngas_e_co2 and the price of oil in $€ / \mathrm{MWh}$, as lnoil_e_co2. For the gas price, the GB NBP day-ahead daily price was used for each hour in the delivery day and for $\mathrm{CO}_{2}$, the EU ETS daily price was used (these data sourced from the Bloomberg Professional data terminal-London Economics). We expect that the value of both of these variables to have a positive, significant effect on the SMP, as intuitively the final price of electricity should be highly dependent on the fuel inputs associated with generating said electricity.

\section{METHODS}

We start with the assumption of a cost function for the Irish electricity system. The cost function is a standard assumption for cost-minimizing behavior and/or perfect competition, ${ }^{4}$ and the since bidding above marginal cost is not allowed, the market design in Ireland probably assures this is a reasonable approximation. Nonetheless more analysis might be considered in order to relax this assumption.

Under the competitive assumptions, the SMP is then equal to the derivative of the cost function with respect to demand. Input prices are considered exogenous, along with demand, and factors such as wind generation and forecast errors are considered as added explanatory variables to the system.

To operationalize the model, we assume the cost function takes the transcendental logarithmic, or translog, form. The translog is a second order Taylor series approximation to an arbitrary cost function ${ }^{5}$ :

$$
\ln C=\alpha+\sum_{i=1}^{N} \alpha_{i} \ln p_{i}+\sum_{k=1}^{M} \alpha_{k} \ln Y_{k}+\frac{1}{2} \sum_{i=1}^{N} \sum_{j=1}^{N} \beta_{i j} \ln p_{i} \ln p_{j}+\frac{1}{2} \sum_{k=1}^{M} \sum_{l=1}^{M} \gamma_{k l} \ln Y_{k} \ln Y_{l}+\sum_{i=1}^{N} \sum_{l=1}^{M} \delta_{i l} \ln p_{i} \ln Y_{l}
$$

Where, $C$, is variable cost, the $p_{i}$ are fuel input prices: $i=\mathrm{gas}(\mathrm{g})$, and oil (o), ${ }^{6}$ the $Y_{k}$ are outputs: $k=\mathrm{demand}(\mathrm{D})$, wind generation $(\mathrm{W})$, and wind forecast error $(\mathrm{F})$. Taking the derivative of the cost function with respect to demand gives the marginal cost function. Since we will work in logs, we take the logarithmic derivative, to give:

$$
\frac{d \ln C}{d \ln Y_{D}}=\alpha_{D}+\gamma_{D D} \ln Y_{D}+\gamma_{D W} \ln Y_{W}+\gamma_{D F} \ln Y_{F}+\delta_{g D} \ln p_{g}+\delta_{o D} \ln p_{o}
$$

And we posit that the SMP is the marginal cost, so:

$$
\frac{d \ln C}{d \ln Y_{D}}=\ln S M P
$$

\footnotetext{
${ }^{4}$ More technically, a utility that minimizes cost subject to a demand constraint with competitive input markets yields the same outcome as perfect competition.

${ }^{5}$ A number of papers introduced the translog cost function, from Christensen, L, D.W. Jorgensen, and L. Lau (1971), "Conjugate Duality and Transcendental Logarithmic Production Functions, Econometrica, 39:4, July, 255-256.

${ }^{6}$ In a previous study by O'Mahoney \& Denny, the coal price was found to be insignificant. We estimate that the coal price infrequently is 'on the margin' and that fuel prices for more flexible generation technologies drive the SMP.
} 
Table 2: Model Results

\begin{tabular}{|c|c|c|c|}
\hline VARIABLES & M1 & M2 & M3 \\
\hline lndem & $\begin{array}{c}1.004 * * * \\
(0.014)\end{array}$ & $\begin{array}{c}1.111 * * * \\
(0.014)\end{array}$ & \\
\hline lnwindgen & $\begin{array}{c}-0.0626 * * * \\
(0.003)\end{array}$ & $\begin{array}{c}-0.0509 * * * \\
(0.003)\end{array}$ & \\
\hline lnwindfc_e & $\begin{array}{c}0.0159 * * \\
(0.007)\end{array}$ & $\begin{array}{c}0.00976 \\
(0.006)\end{array}$ & $\begin{array}{c}0.0311 * * * \\
(0.008)\end{array}$ \\
\hline Mar & & $\begin{array}{c}0.0553^{* * *} \\
(0.018)\end{array}$ & \\
\hline Apr & & $\begin{array}{c}0.199 * * * \\
(0.019)\end{array}$ & \\
\hline May & $\begin{array}{c}0.131 * * * \\
(0.012)\end{array}$ & $\begin{array}{c}0.268 * * * \\
(0.018)\end{array}$ & $\begin{array}{c}0.0777 * * * \\
(0.017)\end{array}$ \\
\hline Jun & & $\begin{array}{c}0.220 * * * \\
(0.018)\end{array}$ & \\
\hline Jul & & $\begin{array}{c}0.257 * * * \\
(0.017)\end{array}$ & \\
\hline Aug & & $\begin{array}{c}0.278 * * * \\
(0.018)\end{array}$ & \\
\hline Sep & $\begin{array}{c}0.135 * * * \\
(0.013)\end{array}$ & $\begin{array}{c}0.2682^{* * * *} \\
(0.018)\end{array}$ & $\begin{array}{c}0.0899 * * * \\
(0.017)\end{array}$ \\
\hline Oct & & $\begin{array}{c}0.1433 * * * \\
(0.017)\end{array}$ & \\
\hline Nov & & $\begin{array}{c}0.0433 * * \\
(0.018)\end{array}$ & \\
\hline jan_feb & & $\begin{array}{l}-0.0120 \\
(0.016)\end{array}$ & \\
\hline lngas_e_co2 & $\begin{array}{c}0.486 * * * \\
(0.026)\end{array}$ & $\begin{array}{c}0.551 * * * \\
(0.029)\end{array}$ & $\begin{array}{c}0.581 * * * \\
(0.033)\end{array}$ \\
\hline lnoil_e_co2 & $\begin{array}{c}0.129 * * * \\
(0.036)\end{array}$ & $\begin{array}{c}0.158 * * * \\
(0.034)\end{array}$ & $\begin{array}{c}0.190 * * * \\
(0.044)\end{array}$ \\
\hline year & $\begin{array}{c}0.0195^{* * *} \\
(0.006)\end{array}$ & & $\begin{array}{c}-0.0259 * * * \\
(0.008)\end{array}$ \\
\hline Indem_wind & & & $\begin{array}{c}0.222 * * * \\
(0.013)\end{array}$ \\
\hline Indem_wind2 & & & $\begin{array}{c}-0.0227 * * * \\
(0.002)\end{array}$ \\
\hline Constant & $\begin{array}{c}-49.414 * * * \\
(12.790)\end{array}$ & $\begin{array}{c}-12.208^{* * * *} \\
(0.268)\end{array}$ & $\begin{array}{c}47.593 * * * \\
(15.666)\end{array}$ \\
\hline Observations & 48,285 & 48,285 & 48,285 \\
\hline R-squared & 0.353 & 0.369 & 0.283 \\
\hline
\end{tabular}

The modeling results show reasonably good fits and most of the variables included are significant. Inclusion of seasonal dummies seems to have a very small impact on the overall size of the regression coefficients of interest. Standard statistical tests of the constraint that the coefficient on the wind generation variable was equal and opposite to the demand variable coefficient rejected the restricted model (we do not report these statistics), but the lower Rsquared of the constrained model ( $28 \%$ vs. $37 \%, 35 \%)$ is an indication of this.

Of key importance is the interpretation of the coefficients. From Model 1, a $1 \%$ increase in demand increases SMP by about $1 \%$. Conversely, a $1 \%$ increase in wind generation decreases SMP by about $0.06 \%$. A $1 \%$ forecast 
error in wind increases SMP by about $0.016 \%$. The results are not largely sensitive to inclusion of a variety of other variables, whereas the model appears sensitive to the assumption about how to model the demand net of wind and the form of this impact (e.g., quadratic or linear). Overall, the size of the cost of wind forecast errors is estimated to be approximately $1 / 5^{\text {th }}$ of the $\%$ marginal cost savings (price) benefit from wind. The absolute cost savings from wind are more in-line with the demand impact, as average demand is roughly ten times average wind generation.

The effective capacity of wind - measured as the maximum wind output per annum - increased by an average of $14.2 \%$ annually over the time period under investigation, from $888 \mathrm{MW}$ in 2008 to $1500 \mathrm{MW}$ in 2012 . Thus, to consider the impacts of both wind and its forecast error for varying capacity levels, we rerun our Model $3^{7}$ specification on an annual basis. Years 2008 and 2009 do not have complete data, therefore we present results from 2010 onwards in Table 3.

Table 3: Annual Results

\begin{tabular}{|c|c|c|c|}
\hline VARIABLES & 2010 & 2011 & 2012 \\
\hline lndem_wind & $\begin{array}{c}0.245 * * * \\
(0.031)\end{array}$ & $\begin{array}{c}0.316 * * * \\
(0.024)\end{array}$ & $\begin{array}{c}0.303 * * * \\
(0.025)\end{array}$ \\
\hline lndem_wind 2 & $\begin{array}{c}-0.0180 * * * \\
(0.005)\end{array}$ & $\begin{array}{c}-0.0318 * * * \\
(0.004)\end{array}$ & $\begin{array}{c}-0.0330 * * * \\
(0.004)\end{array}$ \\
\hline lnwindfc_e & $\begin{array}{c}0.0629 * * * \\
(0.018)\end{array}$ & $\begin{array}{c}0.0820 * * * \\
(0.015)\end{array}$ & $\begin{array}{l}0.0202 \\
(0.014)\end{array}$ \\
\hline lngas_e_co2 & $\begin{array}{c}0.126 \\
(0.121)\end{array}$ & $\begin{array}{l}0.284 * \\
(0.158)\end{array}$ & $\begin{array}{l}0.281^{*} \\
(0.165)\end{array}$ \\
\hline Inoil_e_co2 & $\begin{array}{c}0.632 * * \\
(0.263)\end{array}$ & $\begin{array}{l}-0.339 \\
(0.281)\end{array}$ & $\begin{array}{c}0.317 \\
(0.364)\end{array}$ \\
\hline Jan & $\begin{array}{l}-0.313^{*} \\
(0.164)\end{array}$ & $\begin{array}{c}-0.125^{* * *} \\
(0.048)\end{array}$ & $\begin{array}{c}-0.0726 \\
(0.066)\end{array}$ \\
\hline $\mathrm{Feb}$ & $\begin{array}{c}-0.248 * * * \\
(0.096)\end{array}$ & $\begin{array}{l}-0.0503 \\
(0.040)\end{array}$ & $\begin{array}{l}-0.0821 \\
(0.069)\end{array}$ \\
\hline Mar & $\begin{array}{c}-0.287 * * * \\
(0.097)\end{array}$ & $\begin{array}{l}-0.0394 \\
(0.043)\end{array}$ & $\begin{array}{l}-0.112 \\
(0.080)\end{array}$ \\
\hline Apr & $\begin{array}{c}-0.281 * * * \\
(0.090)\end{array}$ & $\begin{array}{l}0.0219 \\
(0.053)\end{array}$ & $\begin{array}{l}-0.0026 \\
(0.072)\end{array}$ \\
\hline May & $\begin{array}{l}-0.0661 \\
(0.084)\end{array}$ & $\begin{array}{c}0.123 * * * \\
(0.040)\end{array}$ & $\begin{array}{c}-0.0359 \\
(0.063)\end{array}$ \\
\hline Jun & $\begin{array}{l}-0.0920 \\
(0.080)\end{array}$ & $\begin{array}{c}-0.0818^{* *} \\
(0.041)\end{array}$ & $\begin{array}{c}-0.0942 \\
(0.078)\end{array}$ \\
\hline Jul & $\begin{array}{l}0.0309 \\
(0.074)\end{array}$ & $\begin{array}{c}-0.123 * * * \\
(0.045)\end{array}$ & $\begin{array}{l}-0.0661 \\
(0.067)\end{array}$ \\
\hline Aug & $\begin{array}{l}-0.0799 \\
(0.077)\end{array}$ & $\begin{array}{c}-0.0634 \\
(0.039)\end{array}$ & $\begin{array}{l}-0.0300 \\
(0.067)\end{array}$ \\
\hline Sep & $\begin{array}{r}-0.0166 \\
(0.077)\end{array}$ & $\begin{array}{l}0.0575 \\
(0.038)\end{array}$ & $\begin{array}{l}0.0229 \\
(0.063)\end{array}$ \\
\hline Oct & $\begin{array}{l}-0.0811 \\
(0.059)\end{array}$ & $\begin{array}{l}-0.0465 \\
(0.037)\end{array}$ & $\begin{array}{c}-0.0678 \\
(0.060)\end{array}$ \\
\hline Nov & $\begin{array}{c}-0.0934 * \\
(0.049)\end{array}$ & $\begin{array}{c}-0.00083 \\
(0.038)\end{array}$ & \\
\hline Constant & $\begin{array}{l}-0.7168 \\
(1.989)\end{array}$ & $\begin{array}{l}1.5739 \\
(2.026)\end{array}$ & $\begin{array}{r}-1.3228 \\
(2.743)\end{array}$ \\
\hline Observations & 15,714 & 17,493 & 15,078 \\
\hline R-squared & 0.478 & 0.510 & 0.573 \\
\hline
\end{tabular}

\footnotetext{
${ }^{7}$ Allowing the coefficient's to change by year M3 gave the best fits.
} 
The effect of wind forecast error in our annual specifications is greater than in our previous versions. In 2010 , a $1 \%$ increase in wind forecast error increases SMP by about $0.06 \%$ and in 2011 by $0.08 \%$. In 2012, wind forecast error is not a statistically significant driver of the SMP.

Demand net of wind and its square are statistically significant in all three annual specifications. We find that net demand has a positive effect on SMP, and that the effect is increasing at a decreasing rate in each year (similar to what was found in [6]). Figure 2 presents the non-linear effect separately.

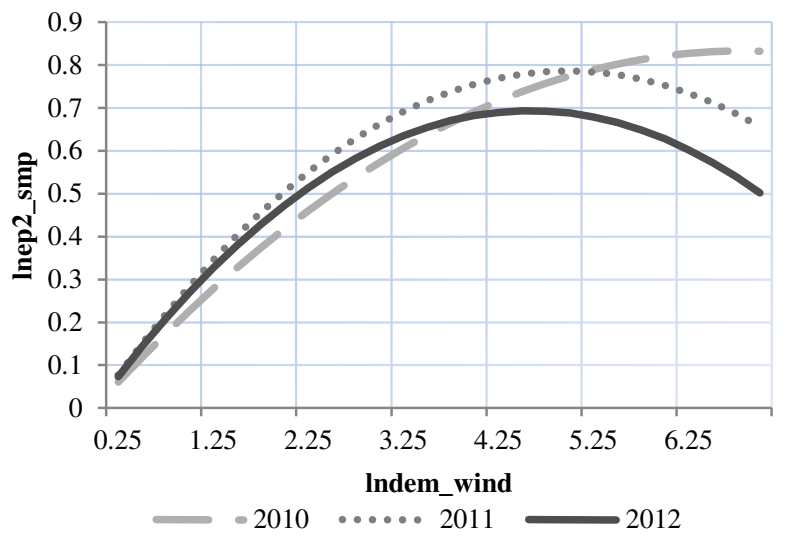

Figure 2 Effect of logged net demand on logged SMP as per annual Model 3 specifications for full range of net demand values in our dataset, ceretis paribus.

In comparing these annual effects, we find that as the effective capacity of wind on the system increases, the effect of net demand (demand net of the met through wind output) is reduced. The effect of wind forecast errors as wind capacity increases on the system is less clear from our analysis. When accounting for variations in effective wind capacity, we find errors to have a greater impact than in the unconstrained version, yet this effect is not always found to be statistically significant.

\section{CONCLUSIONS AND FUTURE DIRECTIONS}

This paper has estimated a model of the marginal impact of wind generation on system costs in Ireland. Overall, the results are good in the sense of good fits, significant variables, and grounding in theory; the paper advances on previous work [6] in that the derivation of the cost function is explicit from the SMP definition and the translog form. The estimates of the size of the coefficients are credible and we believe that they should be useful to policy makers when considering what external system costs various levels of wind generation might have on systems sharing similar characteristics with Ireland. We thus conclude that the econometric approach to estimating the cost of wind external system costs should be considered in future studies and system planning.

While the paper, we believe, advances the state of knowledge of the external costs of wind generation, many caveats should be kept in mind, such as the impacts of other factors such as interconnection, generation capacity mix, other flexibility parameters, market rules, etc.

The comparison with previous studies is interesting, and qualitatively our results are somewhat similar to [6] with the impact of wind net of demand on cost increasing at a decreasing rate, but comparison of like-with-like is difficult because of the different market designs and available data, so comparisons should be made with due caution.

With this in mind, the paper suggests some particular areas for future research. First, studies across other jurisdictions would be interesting. Second, and perhaps more curiously, the sensitivity of the model and rejection of the constraint that wind generation should have an equal and opposite impact to demand on SMP is surprising and suggests more testing of different functional forms. We are not aware of other studies which tested this hypothesis 
and thus this likely warrants further research. The need to track impacts as wind penetration grows is also suggested by our results.

\section{REFERENCES}

Periodicals:

[1] M. Black and G. Strbac, "Value of Storage in Providing Balancing Services for Electricity Generation Systems with High Wind Penetration," Journal of Power Sources, vol. 162, pp. 949-953, 2006.

[2] E. Denny and M. O'Malley, "Quantifying the Total Net Benefits of Grid Integrated Wind." Power Systems, IEEE Transactions on 22(2): 605-615, 2007.

[3] F. A. Felder, "Examining Electricity Price Suppression Due to Renewable Resources and Other Grid Investments." The Electricity Journal In Press, Corrected Proof, 2011.

[4] A. O'Mahoney and E. Denny "Electricity Prices and Generator Behaviour in Gross Pool Electricity Markets", Energy Policy, Volume 63, December 2013, Pages 628-637

[5] N. Troy, E. Denny, et al., "Base-Load Cycling on a System with Significant Wind Penetration." Power Systems, IEEE Transactions on 25(2): 1088-1097, 2010.

[6] Swinand, G.P.; Godel, M.; , "Estimating the impact of wind generation on balancing costs in the GB electricity markets," European Energy Market (EEM), 2012 9th International Conference on the , vol., no., pp.1-8, 10-12 May 2012

\section{Technical Reports:}

[7] R. Gross, P. Heptonstall, D. Anderson, T. Green, M. Leach and J. Skea. (2006). The Costs and Impacts of Intermittency: An assessment of the evidence on the costs and impacts of intermittent generation on the British electricity network. A report of the Technology and Policy Assessment Function of the UK Energy Research Centre.

[8] H. Holttinen, P. Meimborn, A. Orths, B. Lange, M. O’Malley, J. O. Tande, A. Estanqueiro, E. Gomez, L. Soder, G. Strbac, J. C. Smith, and F. van Hulle (2009), "Impacts of Large Amounts of Wind Power on Design and Operation of Power Systems: Results of IEA Collaboration,” IEA Task 25 Homepage. Available at: www.IEAwind.org

Data Sources:

[9] Market schedules of the Irish Single Electricity Market. Available: http://www.sem-o.com/Pages/default.aspx

[10] System Demand and Wind Generation Data for the Irish Single Electricity Market. Available: http://www.eirgrid.com/ 


\section{BIOGRAPHY}

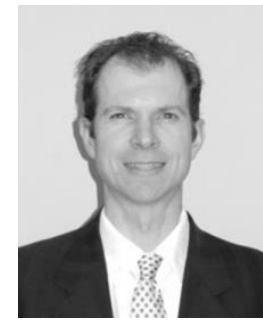

Greg Swinand is a Partner with London Economics and is the leader of LE's international work on energy, environmental, and electricity economics. He previously was a visiting professor in the Department of Economics at Babson College and has a $\mathrm{PhD}$ in economics from Boston College and an MSc in Resource Economics from the University of Massachusetts-Amherst.

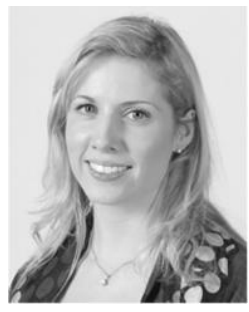

Amy O'Mahoney is a Senior Consultant with IPA Energy + Water Economics in the Regulation Department. She previously was a postdoctoral researcher in Trinity College, Dublin and has a PhD in Economics from Trinity College Dublin. She received BComm and MSc degrees from NUI Galway. Her research interests relate to energy and environmental economics, and the economics of renewable generation and electricity markets in particular. 